Supplement of Clim. Past, 15, 1581-1601, 2019

https://doi.org/10.5194/cp-15-1581-2019-supplement

(c) Author(s) 2019. This work is distributed under

the Creative Commons Attribution 4.0 License.

(c) (1)

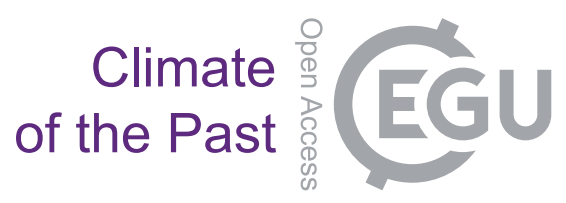

Supplement of

\title{
Dynamic climate-driven controls on the deposition of the Kimmeridge Clay Formation in the Cleveland Basin, Yorkshire, UK
}

Elizabeth Atar et al.

Correspondence to: Elizabeth Atar (elizabeth.atar@gmail.com)

The copyright of individual parts of the supplement might differ from the CC BY 4.0 License. 


\section{Supplement 1}

\section{S1.1 Petrographic methods}

5 A subset of 47 samples was selected based on lithological variability and prepared as thin sections. Samples were prepared to $30 \mu \mathrm{m}$ thickness and polished with $1 \mu \mathrm{m}$ diamond paste. Examination and imaging of the thin sections was conducted on a Leica DM750P microscope fitted with a Leica ICC50 HD camera. Samples were coated with $30 \mathrm{~nm}$ of carbon before being examined on the Hitachi SE-70 High Resolution Analytical Scanning Electron Microscope. The samples were divided up into microlithofacies based on composition, texture and bedding features, following the nomenclature guidelines set out by

10 (Lazar et al., 2015).

\section{S1.2 Sample powdering}

All 116 samples were powdered to c. $10 \mu \mathrm{m}$ grain size using an agate Retsch, RS200, Vibratory Disc Mill and stored in air tight glass jars. It is worth noting that due to average sample thicknesses of $1 \mathrm{~cm}$, the geochemical compositions of individual samples might represent mixed signals that would not resolve any sub-cm scale geochemical variability.

\section{S1.3 LECO analysis}

116 samples were prepared for total organic carbon (TOC) measurements by decalcification in hot $\left(60-70^{\circ} \mathrm{C}\right) 12.5 \mathrm{ml} \mathrm{HCl}$ before being rinsed in water and dried. Both TOC and total carbon (TC) were measured on bulk powders using a LECO

20 CS230 Carbon-Sulphur analyser at Newcastle University. Accuracy was measured to $0.08 \%$ for TC and $0.14 \%$ for TOC calculated to a reference soil. $\mathrm{CaCO}_{3}$ concentrations were calculated as $\mathrm{CaCO}_{3}=(\mathrm{TC}-\mathrm{TOC}) * 8.33$.

\section{S1.4 Organic carbon isotope analysis}

Prior to the analysis of the stable isotope composition of organic carbon $\left(\delta^{13} \mathrm{C}_{\mathrm{org}}\right), 114$ ground samples were mixed with $5 \%$ hydrochloric acid and left overnight to remove the carbonate fraction. Samples were then rinsed until neutral and dried overnight at $40^{\circ} \mathrm{C}$. Treated samples were homogenized with an agate pestle and mortar prior to analysis. $\delta^{13} \mathrm{C}_{\text {org }}$ analyses were performed by combustion in a Costech ECS4010 Elemental Analyzer connected to a VG TripleTrap and Optima dualinlet mass spectrometer, with $\delta^{13} \mathrm{C}_{\text {org }}$ values calculated to the VPDB standard using within-run laboratory standards calibrated against NBS18, NBS-19 and NBS 22. Precision of $\pm<0.1 \%$ (1 SD) was recorded.

\section{S1.5 XRF analysis}


Major ( $\mathrm{Si}, \mathrm{Ti}, \mathrm{Al}, \mathrm{Fe}$, and $\mathrm{Mn}$ ) and selected trace element (As, Co, Cr, Cu, Mo, V, U, Zn and Zr) contents were obtained on 116 samples through Wavelength-Dispersive X-Ray Fluorescence (XRF) analyses at the ICBM (University of Oldenburg). $0.7 \mathrm{~g}$ of ground sediment was mixed with $4.2 \mathrm{~g}$ of $\mathrm{Li}_{2} \mathrm{~B}_{4} \mathrm{O}_{7}$ and $1.0 \mathrm{~g}$ of $\left(\mathrm{NH}_{4}\right)_{2} \mathrm{NO}_{3}$ (oxidizing agent) and fused to a borate glass bead at $1350^{\circ} \mathrm{C}$ in a platinum crucible. The composition of the beads was measured using a Philips PW-2400 WD-XRF

5 spectrometer. Precision was measured at $<0.5 \%$ for major elements and $<7 \%$ for trace elements, excluding $U$ for which precision was measured at $16 \%$. Major and trace elements are expressed as wt \% and ppm, respectively.

All elements were normalised to Al to allow for assessment of relative concentration changes irrespective of variable dilution by organic matter or carbonate. Aluminium is chosen as representative of the siliciclastic fine grained sediment fraction due to its generally high contents in the samples and its limited involvement in biological, redox and diagenetic processes (Tribovillard et al., 2006). Element/Al ratios are expressed as $\mathrm{wt} \% / \mathrm{wt} \%$ or ppm/wt\% as appropriate.

Enrichment factors of selected trace elements are calculated as:

$$
\mathrm{EF}=(\text { element } / \mathrm{Al})_{\text {organic rich interval }} /(\text { element/Al) } \mathrm{UCC}
$$

15 Adapted from Brumsack (2006), with $\mathrm{EF}>1$ indicating relative enrichment compared to the background sediment, while $\mathrm{EF}<1$ indicates relative depletion. We choose to calculate EF relative to UCC sediment rather than the frequently applied average shale (Wedepohl, 1991) due to clear and systematic deviations of both conservative and redox-related elements and derived element/Al ratios from the average shale composition, which would result in misleading EF patterns.

\section{S1.6 ICP-MS analysis}

Selected trace elements (Mo, Cd, U, V, Re, Tl, W, As, and Sb) concentrations were obtained of a subset of 50 samples. Trace metals were measured in acid digestions by Quadrupole Inductively Coupled Plasma Mass Spectrometry (Q-ICP-MS; iCAP Q, Thermo Fisher Scientific) coupled to a PrepFast automated dilution device (ESI). About $50 \mathrm{mg}$ of ground sediment powder were digested in closed Teflon vessels at $180^{\circ} \mathrm{C}$ for $12 \mathrm{~h}$ using a mixture of $\mathrm{HNO}_{3}$, $\mathrm{HF}$, and $\mathrm{HClO}_{4}$. After digestion, the acids were evaporated at $\max .200^{\circ} \mathrm{C}$ on a heated block, fumed-off three-times with semi-concentrated $\mathrm{HCl}$, and finally diluted to $50 \mathrm{~mL}$ with $2 \mathrm{Vol}_{\%} \mathrm{HNO}_{3}$. All acids used were of suprapure quality. ICP-MS measurements were performed by using $\mathrm{He}$ as collision gas, an external calibration, and with $\mathrm{Be}, \mathrm{Ga}, \mathrm{In}, \mathrm{Rh}$, and Ir as internal standards. The final dilution factor of the measured acid digestions was 5,000. The samples from the Landsort Deep were treated in the same way as described above. In addition to trace metal analysis by ICP-MS, Al and Mn were determined by Inductively Coupled Plasma Optical Emission Spectrometry (iCAP 7400 Duo, Thermo Fisher Scientific) from 1,000-fold diluted acid digestions and Sc as internal standard. Precision and trueness were checked by replicate measurements $(n=14)$ of the international reference material SGR-1b (USGS) and were better than $3.6 \%$ and $11.3 \%$, respectively. For informative or missing reference values of SGR-1b, the GeoReM database (Jochum et al., 2005) was used. 
The ICP-MS derived element data were processed analogous to the XRF derived element data regarding the normalisation to $\mathrm{Al}$ and the calculation of enrichment factors.

\section{S1.7 Mercury $(\mathrm{Hg})$ analysis}

5 The contents of $\mathrm{Hg}$ were determined from $\sim 100 \mathrm{mg}$ of sediment material by a direct mercury analyser (DMA80, Milestone). Precision and trueness were checked with the certified reference materials BCR-142R (Community Bureau of Reference) and TH-2 (National Water Research Institute, Canada) and were better than 3\% and $-1.0 \%$, respectively.

\section{References}

Brumsack, H.-J., The trace metal content of recent organic carbon-rich sediments: Implications for Cretaceous black shale formation. Palaeogeography, Palaeoclimatology, Palaeoecology, 232(2-4): 344-361, 2006.

Jochum, K.P., Nohl, U., Herwig, K., Lammel, E., Stoll, B. and Hofmann, A.W., GeoReM: a new geochemical database for reference materials and isotopic standards. Geostandards and Geoanalytical Research, 29(3), pp.333-338, 2005.

Lazar, O.R., Bohacs, K.M., Schieber, J., Macquaker, J.H., Demko, T.M., Mudstone Primer: Lithofacies Variations, Diagnostic Criteria, and Sedimentologic-stratigraphic Implications at Lamina to Bedset Scales. SEPM (Society for Sedimentary Geology), 2015.

Tribovillard, N., Algeo, T.J., Lyons, T., Riboulleau, A., Trace metals as paleoredox and paleoproductivity proxies: An update. Chemical Geology, 232(1-2): 12-32, 2006. 
Supplement 2

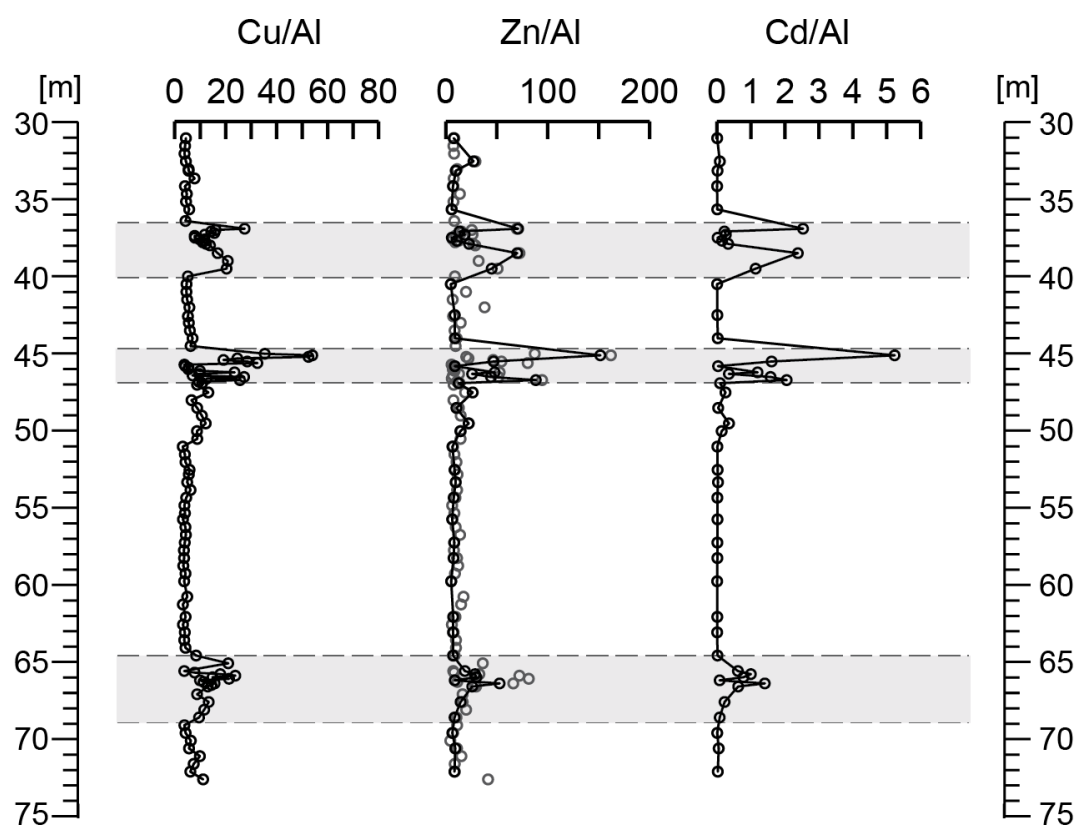

Figure S2: Dpeth $\log$ plots of $\mathrm{Cu} / \mathrm{Al}, \mathrm{Zn} / \mathrm{Al}$, and $\mathrm{Cd} / \mathrm{Al}$ for the Ebberston 87 core. Grey panels depict the higher variability 5 mudstone intervals (HVMIs). 
Supplement 3

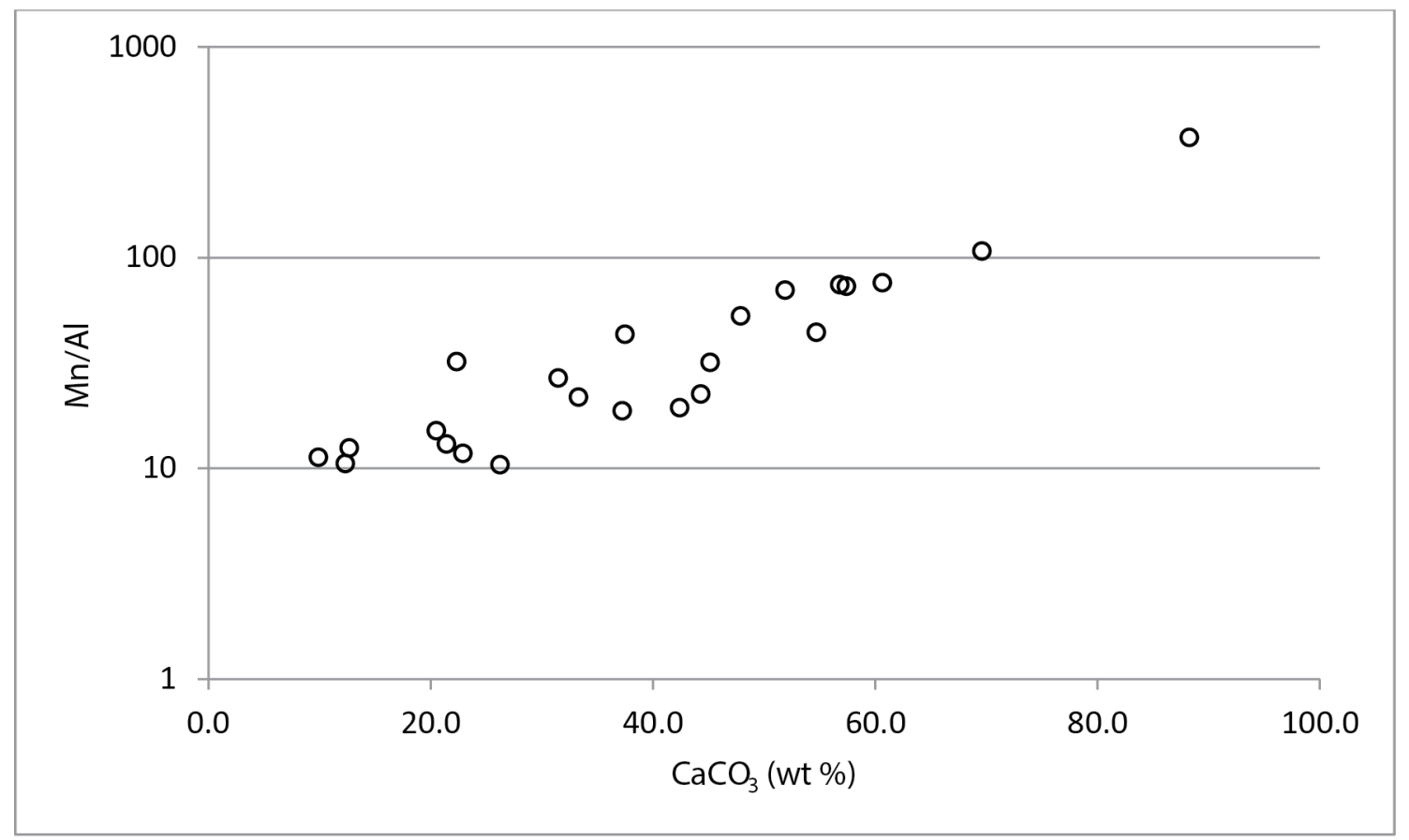

Fig S3: Mn/Al plotted against $\mathrm{CaCO}_{3}$ contents for the higher variability mudstone intervals (HVMIs). Note the logarithmic y axis. 
Supplement 4

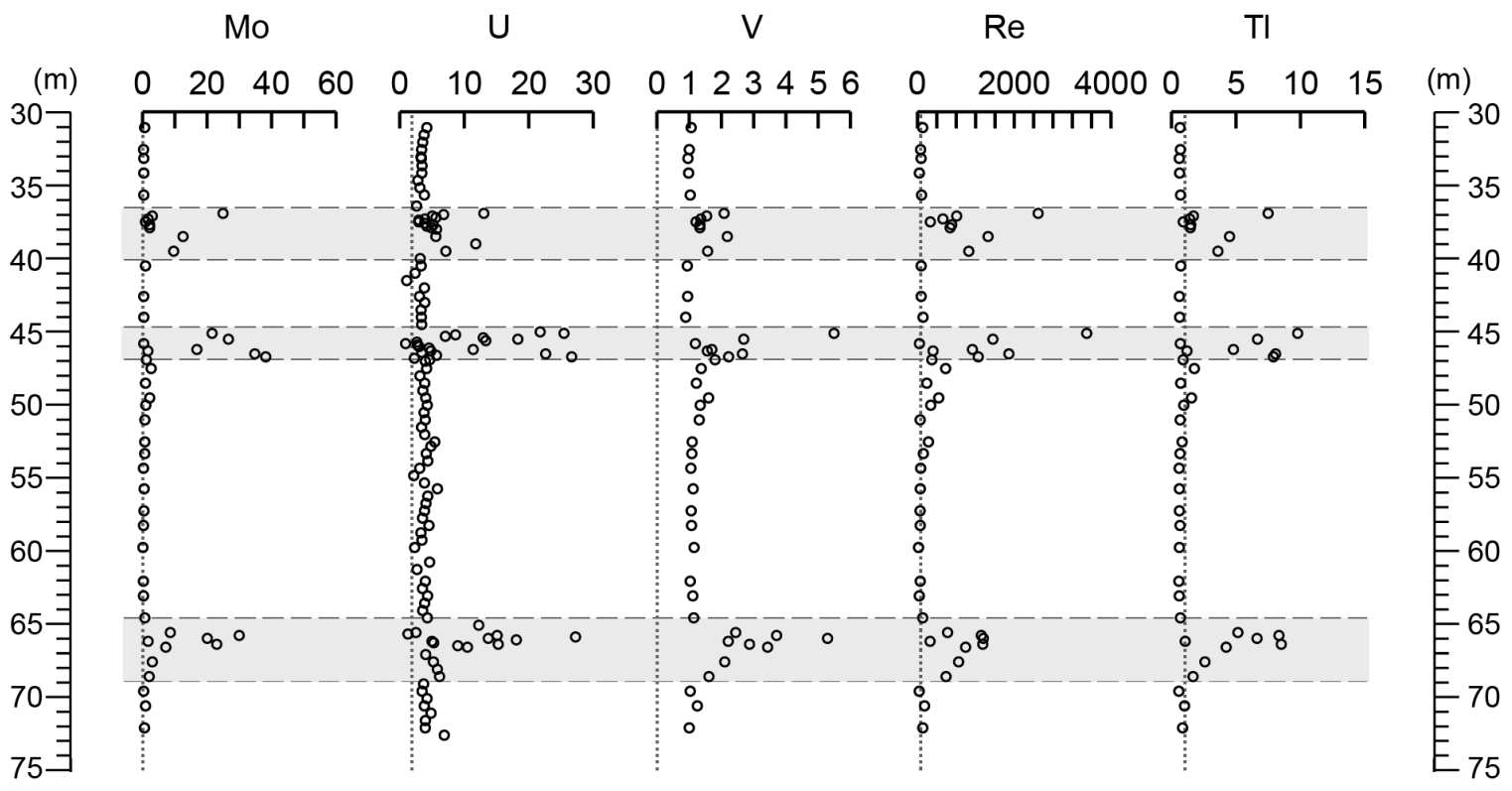

$\begin{array}{llllll}\text { As } & \mathrm{Sb} & \mathrm{Hg} & \mathrm{Cu} & \mathrm{Zn} & \mathrm{Cd}\end{array}$

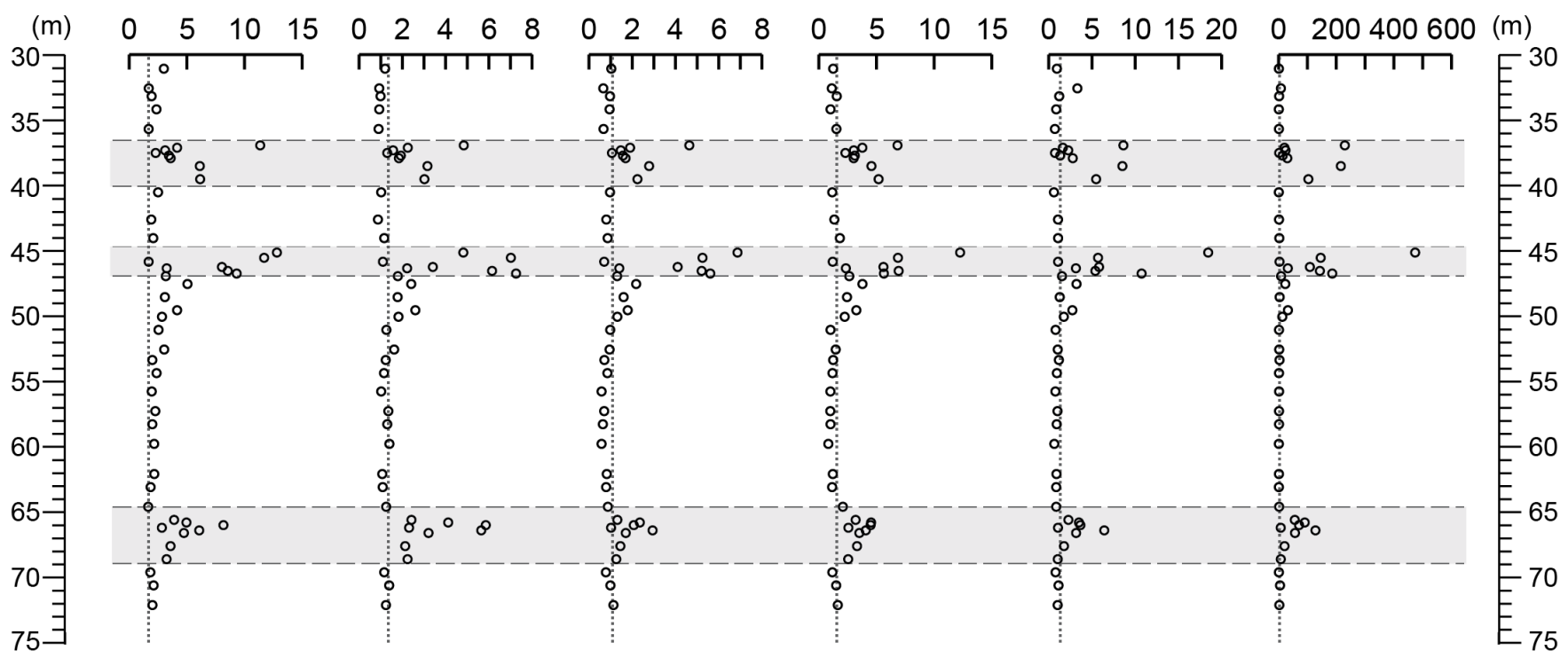

Figure S4: Enrichment factors for the studied section calculated relative upper continental crust (UCC: Rudnick and Gao, 2003). 